\title{
Medidas de la Felicidad Nacional Bruta ${ }^{1}$
}

\section{Measures of Gross National Happiness ${ }^{1}$}

\author{
Ruut Veenhoven \\ Erasmus University Rotterdam
}

Resumen. La felicidad está abriéndose hueco en la agenda política, lo cual reclama medir el éxito alcanzado por los distintos países en crear felicidad para un gran número de personas, de un modo análogo a las medidas del éxito en la creación de riqueza, como el PNB. La felicidad se define como el disfrute subjetivo de la propia vida como un todo, y puede medirse por medio de autoinformes. En la actualidad se aplican encuestas a gran escala a la población general de distintos países en las que se hacen preguntas sobre la felicidad. Disponemos de datos comparables sobre felicidad en 144 países y de series temporales de 25 años o más en 11 países desarrollados.

Los datos pueden combinarse de distintos modos. Si el objetivo es sólo medir un mayor grado de felicidad para el mayor número de ciudadanos, la medida idónea es la "felicidad media" (FM). Si el énfasis se pone en la felicidad duradera, habrá que combinar la felicidad media con la longevidad con el fin de obtener el índice de "años de vida feliz" (AVF). Si se pretende disminuir las diferencias entre los ciudadanos, el indicador relevante es la "desigualdad en felicidad" (DF) entre países, utilizando la desviación típica. La media y la dispersión pueden también combinarse para obtener un índice de "felicidad ajustada a la desigualdad" (FAD).

La comparación entre países pone de manifiesto notables diferencias en todas estas medidas de Felicidad Nacional Bruta, divergencia que se corresponde con características sociales sobre las que pueden actuar los responsables políticos, tales como la libertad y la justicia. La comparación temporal muestra una gran evolución durante el último decenio.

Palabras clave: utilitarismo en las normas ("rule-utilitarianism”), indicadores de políticas, felicidad, años de vida feliz, desigualdad en felicidad, internacional, tendencias.

\begin{abstract}
Happiness is rising on the political agenda and this calls for measures of how well nations perform in creating great happiness for a great number, analogous to measures of success in creating wealth, such as GDP.

Happiness is defined as subjective enjoyment of one's life as-a-whole and this can be measured using self-reports. Question on happiness are currently used in large scale surveys of the general population in nations. As a result we have now comparable data on happiness in 144 contemporary nations and time-series of 25 years and longer on 11 developed nations. These data can be aggregated in different ways: If the aim is simply greater happiness for a greater number of citizens, Average happiness (AH) is an appropriate measure. If the focus is on enduring happiness, it is better to combine average happiness with longevity in an
\end{abstract}

La correspondencia se le puede enviar a al autor a través del correo electrónico:veenhoven@fsw.eur.nl

Traducción de este artículo realizada por José María Puente Ontanilla. Supervisión terminológica de Ferrán Casas.
1 Se publicó una versión anterior de este trabajo en Statistics, Knowledge Policy 2007, Measuring and fostering the progress of societies [Estadística, políticas sobre el conocimiento 2007: la medición y el fomento del progreso en las sociedades]. OECD Publishing, ISBN 97892-64-04323-7, capítulo 16, pp 232-253. General Economics \& Future Studies, 2008: 6. 
index of Happy Life Years (HLY). If the aim is to reduce disparity among citizens a relevant indicator is the Inequality of Happiness $(\mathrm{IH})$ in the nations as measured with the standard deviation. Average and dispersion can also be combined in an index of Inequality-Adjusted Happiness (IAH).

Comparison across nations shows sizable differences on all these measures of gross national happiness and these differences correspond with societal characteristics that can be influenced by policy makers, such as freedom and justice. Comparison over time shows major improvement during the last decade.

Key words: rule-utilitarianism, policy indicators, happiness, happy life years, inequality of happiness, cross-national, trend.

\section{Introducción}

La carrera por mejorar el destino de los hombres se inicia en el intento por aliviar sufrimientos como el hambre y las epidemias. Conseguido esto, la atención se desplaza a metas más amplias y positivas. Este es el motivo del aumento actual del interés por la "felicidad", que vuelve a traer a escena un bagage filosófico clásico.

\section{El principio de la máxima felicidad}

Hace dos siglos, Jeremy Bentham (1789) propuso un nuevo principio moral. Afirmaba que la bondad de una acción no debería juzgarse por la decencia de su intención sino por sus consecuencias sobre la felicidad humana. Sostenía que deberíamos buscar la "máxima felicidad para el mayor número de personas". Bentham define la felicidad, en cuanto sentimiento subjetivo, como "la suma de placeres y aflicciones". A esta filosofía se la denomina "utilitarismo" por su énfasis en la utilidad de las consecuencias comportamentales. Hubiera sido preferible llamarla "felicidismo", ya que esta utilidad es considerada como una contribución a la felicidad.

Cuando se aplica al nivel de decisión individual dicha teoría tropieza con algunas dificultades. Una de ellas es que con frecuencia es difícil prever cuál será el balance de los efectos sobre la felicidad de una acción particular: por ejemplo, si la humanidad va a ser más feliz si eliges ser médico. Otro problema es que la teoría considera amoral el comportamiento bienintencionado si resulta negativo.
Imaginemos a una tierna madre que salva la vida a un hijo enfermo el cual cuando llega a mayor es un criminal. No es fácil que las madres prevean el futuro de sus hijos, por lo que difícilmente se les puede reprochar su amor de madre incondicional.

La teoría es más adecuada para valorar reglas generales como la que dice que las madres deben cuidar de sus hijos enfermos. Resulta bastante evidente que seguir esta regla redundará en la felicidad de muchos. Es pues moralmente correcto actuar de acuerdo con tales reglas a pesar de que en alguna ocasión tengan consecuencias negativas. Esta variante se conoce como el "utilitarismo de las normas".

\section{Su aplicación a las políticas públicas}

El utilitarismo de las normas puede utilizarse en legislación como guía moral, habiendo tenido un papel importante en los debates sobre las leyes de la propiedad y la pena de muerte. Dicho principio puede aplicarse también en asuntos más generales de las políticas públicas como la cuestión del grado tolerable de desigualdad en la renta. Esta variante del principio de la mayor felicidad no ha tenido aún demasiado relieve en las políticas públicas, al menos explícito. Está ganando terreno actualmente sobre todo en el Reino Unido (Donovan et al., 2003; Layard, 2005).

La felicidad puede mejorarse a dos niveles: individual y colectivo. En el primero puede aumentarse mediante la información, la formación y el consejo a los ciudadanos. Es especialmente útil en los países 
modernos, en los que se disfruta de unas condiciones sociales tan buenas que la mayor parte de la varianza en felicidad se debe a diferencias individuales. Al nivel colectivo la felicidad puede mejorarse aumentando la habitabilidad en instalaciones públicas como escuelas, organizaciones laborales y residencias de ancianos. Puede aumentarse también la felicidad si se mejora la habitabilidad en el conjunto de la sociedad, por ejemplo facilitando un adecuado nivel de vida y un clima de confianza. Sobre estos detalles me he extendido en otros artículos (Veenhoven, 1994, 2008b).

\section{La necesidad de medir la felicidad}

Aumentar la felicidad de un mayor número de personas precisa de la medición de la misma, necesaria para valorar si la felicidad puede mejorarse de un modo realista, elegir mediante qué medios aumentarla y por último para evaluar la efectividad.

Las medidas de felicidad utilizadas varían algo en función del nivel de intervención. Al nivel individual se necesitan medidas sensibles de la felicidad de las personas, mientras que al nivel colectivo se necesitan agregados globales.

\section{El plan de este artículo}

En este artículo me centro en las medidas de la felicidad a nivel global, es decir, medidas de la felicidad en distintos países. Estas medidas informan a los responsables públicos a cerca de la felicidad de la mayoría. Tales medidas sirven para valorar la eficacia de un país en mejorar la felicidad, amen de para realizar una comparación entre países y a lo largo del tiempo. Como tales, son comparables a indicadores económicos del tipo del PNB por cápita, que indica el éxito de un país en crear riqueza. Por analogía las denomino medidas de "Felicidad Nacional Bruta”2.

\footnotetext{
2 El término "Felicidad Nacional Bruta" (FNB) lo acuñó el Gobierno de Bután para referirse a su programa político no centrado exclusivamente en el desarrollo económico sino también en la conservación de la tradición y de la naturaleza. Felicidad, en el sentido de satisfacción en la vida, no se menciona como meta, por lo que aún no se ha medido como tal en Bután.
}

Como primer paso diferencio la felicidad de otras características de la vida y defino el concepto (sección 2). Luego considero de qué modo puede medirse la felicidad, para concluir que puede lograrse utilizando preguntas directas en estudios de encuesta (sección 3). También presento cuatro aplicaciones de los datos procedentes de encuestas sobre la felicidad en distintos países (sección 4). Reviso los resultados de estas mediciones, primero los relativos al grado de felicidad en los distintos países (sección 5 ), segundo aquellos que muestran las tendencias en felicidad a lo largo del tiempo (sección 6) y por último los resultados referidos a características globales (sección 7).

\section{¿Qué es la felicidad?}

La palabra "felicidad" se utiliza de muchas maneras. En su sentido más amplio es un cajón de sastre para referirse a todo lo que es bueno. En cuanto tal es a menudo intercambiable con términos como "bienestar" o "calidad de vida". A continuación expondré cuatro tipos de calidad de vida para demostrar que el concepto de felicidad encaja sólo en una de ellas.

\section{Cuatro calidades de vida}

Los conceptos de calidad de vida pueden clasificarse según dos distinciones que conjuntamente generan una matriz de $4 \times 4$. Esta clasificación se aborda con mayor extensión en Veenhoven (2000c). La primera distinción es entre oportunidades y resultados, es decir la diferencia entre las oportunidades de disfrutar de una buena vida y llevar realmente una buena vida. La segunda diferenciación es entre calidad de vida externa e interna, en otras palabras entre características "externas" e "internas". En el primer caso la calidad reside en el entorno y en el segundo en la persona. Lane (1994) matizó esta distinción diferenciando entre "calidad de la sociedad" y "calidad de las personas". La combinación de estas dos dicotomías arroja una matriz de cuatro categorías, que se presenta en el cuadro 1 . 
Cuadro 1. Las cuatro cualidades de vida

Cualidades externas

Cualidades internas

Oportunidades vitales

Habitabilidad del entorno

Habilidad de la persona para vivir

\section{La habitabilidad del entorno}

El cuadrante superior izquierdo denota lo que significan unas buenas condiciones de vida, denominadas "habitabilidad". Los ecologistas la conciben en el entorno natural y su descripción abarca aspectos como la polución, el calentamiento global y la degradación de la naturaleza. En la actualidad asocian la habitabilidad con la preservación del medio ambiente. Los urbanistas aplican la habitabilidad al terreno de la construcción, asociándola con temas tales como los sistemas de alcantarillado, la congestión del tráfico o la formación de ghettos. En este caso se considera que la buena vida es fruto de la intervención humana.

Desde el punto de vista sociológico la sociedad ocupa un lugar central, asociándose la habitabilidad con la calidad de la sociedad en conjunto y con la posición que uno ocupa en esta. Habitabilidad no es sinónimo de felicidad en este caso, sino una precondición de la misma. Además no todas las condiciones ambientales conducen del mismo modo a la felicidad.

\section{La habilidad de la persona para vivir}

El cuadrante superior derecho se refiere a los cambios internos en la vida, es decir, en qué medida estamos bien equipados para enfrentarnos a los problemas de la vida. Sen (1992) llama a esta variante de la calidad de vida "capacidad". Yo prefiero el término sencillo de "habilidad para vivir", que contrasta finamente con "habitabilidad"*.

La descripción más común de esta calidad de vida es la falta de defectos funcionales. Un ejemplo

\footnotetext{
* Nota del traductor. El autor se vale de un juego de palabras en inglés entre "life-ability", que traducimos como "habilidad para vivir" y "livability", entendido como "habitabilidad".
}

es la "salud" en sentido limitado, a la que a veces se hace alusión como "salud negativa". Después de la ausencia de enfermedad debe considerarse la calidad de la función, a la que se hace referencia como "salud positiva", asociada con la energía y la resiliencia. Un paso más es evaluar la capacidad bajo una perspectiva evolutiva, incluyendo la adquisición de nuevas destrezas para vivir. Eso es lo que normalmente denota el término "autorrealización". Desde este punto de vista, un hombre de mediana edad no será una persona "adaptada" si se comporta como un adolescente aunque funcione sin problemas a este nivel. Como las aptitudes no se desarrollan en condiciones de inactividad, esta cualidad de la vida está próxima a la "actividad" del concepto aristotélico de eudemonia. Por último, el término "arte de vivir" denota habilidades especiales para vivir. En la mayoría de los contextos esta cualidad se diferencia de la salud mental y en ocasiones se la atribuye a personas ligeramente perturbadas. El arte de vivir se asocia con gustos refinados, capacidad para disfrutar de la vida y estilo original de vida.

La habilidad de afrontar los problemas de la vida por lo general contribuirá a la felicidad tal como se define aquí, pero no es lo mismo. Si se es competente para vivir se tendrán oportunidades de ser feliz, pero este don no garantiza el disfrute como resultado.

\section{La utilidad de la vida}

El cuadrante inferior izquierdo representa la noción de que una buena vida debe ser buena más allá de lo que representa en sí misma. Hay implicados algunos valores elevados. Aún no se ha acuñado un nombre genérico para estos resultados externos de la vida. Gerson (1976:795) se refiere a estos efectos como concepciones "transcendentes" de la cali- 
dad de vida. Otro apelativo es "sentido de la vida", que denota significación "verdadera" por contraposición al mero sentido subjetivo que tiene el término significado. Prefiero el más simple "utilidad de la vida", aunque reconozco que esta etiqueta pude dar también pie a malentendidos.

$\mathrm{Al}$ evaluar los efectos externos de una vida puede considerarse su funcionalidad para el entorno. En este sentido los médicos subrayan lo fundamental que es la vida de un paciente para sus allegados. A un nivel superior la calidad se considera en cuanto a lo que se contribuye a la sociedad. Los historiadores ven calidad en la aportación de las personas a la cultura humana, valorando en este sentido más la vida de los grandes inventores que la de campesinos anónimos. Los moralistas ven calidad en la preservación del orden moral, por lo que valorarán más la vida de un santo que la de un pecador. Ante los muchos efectos que puede tener sobre el entorno la vida de una persona, el número de utilidades es prácticamente infinito.

Además de su utilidad funcional, la vida también se enjuicia por su valor moral o estético. Por ejemplo, la mayoría de nosotros atribuiría mayor calidad a la vida de Florence Nightingale que a la de un borracho, a pesar de que al final sus buenas obras resultaron negativas. En filosofía moral se llama a esto "vida virtuosa", a menudo representada como la esencia de la "verdadera" felicidad.

\section{El significado principal: el disfrute subjetivo de la vida}

Por último, el cuadrante inferior derecho representa los resultados internos de la vida, es decir la calidad según la perspectiva del propio sujeto. Dado que tratamos con seres humanos dotados de conciencia, esta calidad se reduce al disfrute subjetivo de la vida, a la que se alude normalmente con térmi- nos tales como "bienestar subjetivo", "satisfacción en la vida" o "felicidad" en el sentido limitado del término. Es el tipo de felicidad que concebían los filósofos utilitarios y el que se desarrollará aquí.

\section{Los cuatro tipos de satisfacción}

Aunque nos centremos en la satisfacción subjetiva en la vida, aún hay otros significados asociados con la palabra felicidad, significados que pueden igualmente describirse en una matriz de $4 \times 4$. En este caso la clasificación se basa en las siguientes dicotomías: aspectos de la vida por contraposición a la vida como un todo y disfrute pasajero por contraposición a felicidad duradera.

La valoración de la vida puede afectar a aspectos tales como el matrimonio o la vida laboral, o a la propia vida como un todo. La palabra "felicidad" es utilizada en ambos contextos. Por supuesto que tales valoraciones están relacionadas. Disfrutar de aspectos de la vida lógicamente contribuirá a la satisfacción en la vida como un todo (el denominado efecto de abajo arriba) y el disfrute de la propia vida como un todo parece reforzar la satisfacción en aspectos de la vida (efecto de arriba abajo). No obstante, no son temas idénticos. Uno puede estar felizmente casado pero estar insatisfecho de la vida en general o, por el contrario, estar satisfecho de la vida en general a pesar de un matrimonio infeliz. Además, la experiencia de disfrute puede ser breve o duradera. De nuevo se utiliza el término felicidad en ambos casos. A veces se refiere a estados de ánimo pasajeros y otras a satisfacción estable. Una vez más, estos temas están relacionados pero no son lo mismo.

Cuando se combinan, estas distinciones dan lugar a la matriz $4 \times 4$ del cuadro 2 . La distinción entre parte y todo aparece verticalmente y entre disfrute pasajero y duradero horizontalmente.

Cuadro 2 . Los cuatro tipos de satisfacción

\begin{tabular}{lcc}
\hline & Pasajera & Duradera \\
\hline Aspecto de la vida & Placer & Satisfacción con un ámbito \\
Vida como totalidad & Experiencia cumbre & Satisfacción vital (felicidad) \\
\hline
\end{tabular}




\section{Satisfacción instantánea}

El cuadrante superior izquierdo representa el disfrute pasajero de aspectos de la vida. Algunos ejemplos son el placer de una taza de té en el desayuno, la satisfacción de haber realizado una tarea doméstica o el disfrute de una obra de arte. Me refiero a esta categoría como "satisfacciones instantáneas". Kahneman (2000) las denomina "utilidades instantáneas". El cuadrante representa la felicidad hedonista, sobre todo cuando está centrada en la experiencia sensorial. El concepto de felicidad que se utiliza aquí es, no obstante, más amplio: se refiere tanto a la satisfacción global como a la vida como un todo. Aunque el disfrute efímero contribuye obviamente a la valoración positiva de la vida, no la conforma en su conjunto.

\section{Satisfacción con un ámbito}

El cuadrante superior derecho denota aprecio duradero de aspectos de la vida tales como la satisfacción en el matrimonio o en el trabajo. Se refiere habitualmente a la satisfacción con ámbitos concretos. Auque depende normalmente del flujo continuo de satisfacciones instantáneas, este tipo de satisfacción tiene continuidad en sí misma. Por ejemplo, uno puede estar satisfecho con su matrimonio aunque no haya podido disfrutar de la compañía del cónyuge durante algún tiempo. Se alude a la satisfacción con un ámbito particular con el término felicidad: matrimonio feliz, feliz en el trabajo, etc. No obstante, en este capítulo se utiliza el término felicidad en el sentido más amplio de satisfacción global con la vida (y como un todo). Uno no llamaría feliz a una persona que está satisfecha en su matrimonio o en el trabajo pero que es infeliz en general por su mala salud. Incluso sería posible que alguien estuviera satisfecho en todos los ámbitos que uno pudiera imaginar y aun así se sintiera deprimido.

\section{Experiencia cumbre}

El cuadrante superior derecho expresa la combinación de experiencia efímera y aprecio de la vida en general. Esta combinación se da en experiencias cumbre, en las que se producen sentimientos breves pero muy intensos y una percepción de totalidad. Es el tipo de felicidad sobre la que escriben los poetas. Tampoco es el tipo de felicidad de la que hablaremos aquí. Un momento de dicha no es una apreciación duradera de la vida. De hecho, estas experiencias cumbre parecen perjudiciales para la satisfacción duradera, tal vez porque produzcan desorientación (Diener et al., 1989).

\section{El sentido principal: la satisfacción duradera con la propia vida como un todo}

Por último, el cuadrante inferior derecho representa la combinación de satisfacción duradera con la vida como un todo. Es lo que yo quiero decir con la palabra felicidad. Un sinónimo es "satisfacción vital". Es el significado en el que pensaban los filósofos utilitaristas cuando hablaban sobre felicidad. Al hablar de la "suma" de placeres y sufrimiento se referían al equilibrio a lo largo del tiempo, es decir algo duradero.

\section{Definición de felicidad}

La felicidad global es el grado con que una persona juzga favorablemente la calidad global de su propia vida como un todo. En otras palabras: lo que a uno le gusta la vida que uno lleva. Los términos más importantes de la definición se elucidarán a continuación.

Grado. La palabra "felicidad" no se usa para denotar un aprecio óptimo por la vida, sino para referirse a un grado, como los conceptos "longitud" o "peso" denotan más o menos de algo. Al decir que una persona es feliz queremos decir que considera su vida favorablemente más que desfavorablemente.

Persona. El término felicidad se usa únicamente para describir el estado de una persona particular, no se aplica a colectividades. De este modo, no puede decirse que una nación sea feliz; como mucho, que sus ciudadanos se consideran felices.

Juzga. Se utiliza la palabra "felicidad" cuando alguien hace una juicio sobre la calidad de su vida, 
lo cual implica una actividad intelectual. Hacer un juicio global implica evaluar las experiencias pasadas y estimar las experiencias futuras y la calidad media de vida. Esta conceptualización implica que no pueden utilizar la palabra "felicidad" quienes no fueron capaces de decidir. No se puede decir si una persona es feliz o no si dicha persona no es capaz intelectualmente de construir un juicio global...

Favorablemente. Evaluar siempre entraña valorar, es decir, llegar a la conclusión de si a uno le gusta algo o no. El término "felicidad" se refiere únicamente a los juicios relativos a este aspecto. Enjuiciar la felicidad implica una dimensión que se extiende desde la valoración hasta la desvalorización, desde la preferencia a la aversión. Todo ser humano es capaz de hacer valoraciones de este tipo aunque no todos pueden generalizar estas para establecer un juicio sobre la vida como un todo.

Global. La palabra "felicidad" alude a un juicio que integra todos los criterios de valoración utilizados, de modo que la idea de que uno tiene todo lo que siempre ha deseado no necesariamente hace feliz a una persona. A pesar de todos los atributos materiales, dicha persona puede sentirse afligida o deprimida. Tampoco considerar que uno lleva una vida "emocionante" necesariamente le hace a uno feliz: la vida puede ser demasiado emocionante para poder disfrutarse. Dice una maldición china: "que te lo pases bien".

La propia vida. El término "felicidad" se refiere la evaluación de la propia vida, no de la vida en general. Una "Weltanschauung" pesimista no necesariamente caracteriza a alguien como "infeliz".

Como un todo. No utilizamos la palabra "felicidad" para caracterizar la satisfacción relativa a aspectos específicos de la vida, como el matrimonio o el trabajo, sino para referirnos a la satisfacción en la vida en su conjunto.

\section{Componentes de la felicidad}

Los seres humanos son capaces de evaluar su vida de distintas maneras. Compartimos con los animales superiores la posibilidad de valorar afectivamente nuestra situación. Nos sentimos bien o mal en relación a determinadas cosas y nuestro nivel de ánimo indica adaptación general. Como en los animales, estas valoraciones afectivas son automáticas pero, a diferencia de ellos, se sabe que las personas pueden reflexionar sobre dicha experiencia. Tenemos una idea sobre cómo nos sentimos el año pasado, cosa que no ocurre con los gatos. Las personas pueden valorar cognitivamente la vida comparando la vida como es, con cómo debería ser.

La mayor parte de las valoraciones parten de ambas fuentes de información: la valoración afectiva intuitiva y la evaluación cognitiva. La combinación de ambas depende principalmente del objeto: las cosas tangibles, como la renta, se suelen evaluar mediante la comparación y las intangibles, como la atracción sexual, mediante la sensación que producen.

Así es que, para evaluar nuestra vida como un todo, podemos pues utilizar dos fuentes de información: nuestros afectos y nuestros pensamientos. Podemos considerar que nos sentimos bien casi siempre y también que la vida parece satisfacer nuestras exigencias (conscientes). Ambos tipos de valoración no tienen por qué coincidir. Podemos sentirnos bien en general pero aun así ser conscientes de que no conseguimos hacer realidad nuestras aspiraciones, o ver cumplidas estas pero no obstante sentirnos desgraciados.

Utilizar la palabra "felicidad" en ambos casos da lugar a tres tipos distintos de felicidad: la valoración general descrita anteriormente y estos dos tipos específicos de valoración. Al hablar de los componentes nos referimos al "nivel hedónico de afecto" y a la "satisfacción". Para diferenciarlo del juicio concomitante me referiré a la felicidad (el concepto nuclear) como felicidad global.

Nivel hedónico de afecto. Se refiere a la medida en que son agradables los distintos afectos que podemos experimentar, lo que generalmente se traduce en "estado de ánimo". El nivel medio hedónico de afecto de una persona puede medirse en distintos periodos de tiempo: una hora, una semana, un año o toda la vida. El énfasis aquí se pone en el nivel hedónico "característico", es decir, la media en un largo periodo de tiempo, como un mes o un año. El concepto no da por supuesto que haya conciencia subjetiva de dicho nivel medio.

Satisfacción. Es el grado en que una persona percibe que se cumplen sus aspiraciones. El concepto 
presupone que la persona ha desarrollado algunos deseos conscientes y se ha formado una idea sobre su cumplimiento. El que esta idea se ajuste o no a los hechos, es otra cuestión. El concepto alude a la percepción subjetiva de la persona.

Predominio del afecto. Normalmente se da por hecho que el componente cognitivo domina el juicio global sobre la vida (por ejemplo, Easterlin, 1984 y Layard, 2005). Pero hay claros indicios de que la felicidad global se asienta en el nivel hedónico de afecto en primera instancia (Veenhoven, 2008a).

\section{Sinónimos}

Al concepto de "felicidad global" definido hasta aquí se le denomina con diferentes términos. En los años cincuenta se utilizaban a veces con este sentido las palabras ajuste y moral y desde los años sesenta se empezó a utilizar el término satisfacción vital. El término bienestar subjetivo, abreviadamente SWB en inglés, fue introducido por Ed Diener en 1984, y aún predomina en psicología.

La denominación satisfacción vital se utiliza sobre todo para la "felicidad global", pero en algunos casos se refiere a su componente cognitivo, siendo así sinónimo de "satisfacción". En tal contexto el término felicidad se suele utilizar para la valoración afectiva de la vida, por lo que es sinónimo de "nivel hedónico de afecto".

El término bienestar subjetivo se utiliza también en sentido más amplio que el de la felicidad tal y como se la ha definido aquí. A veces alude al buen funcionamiento mental, en el sentido de la capacidad para la vida que aparece en el cuadrante superior derecho de la tabla 1. En otras ocasiones el término se usa como genérico de todo disfrute subjetivo, que abarca todos los cuadrantes de la tabla 2 .

\section{¿Puede medirse la felicidad?}

Hace mucho tiempo que se considera a la medición como una evaluación "objetiva" y "externa". Ya sabemos que la felicidad no puede medirse así. No se han descubierto correlatos sólidos y probablemente nunca se descubrirán, como tampoco se han descubierto comportamientos manifiestos que guarden una relación sistemática con el disfrute interior de la vida. Como la mayoría de los fenómenos actitudinales, la felicidad se traduce sólo en parte en comportamiento. El comportamiento suicida es un ejemplo: aunque la mayoría de los suicidas sean infelices sólo una minoría de infelices se suicida.

Por definición, la felicidad es algo que tenemos en la mente y por lo tanto podemos medirla haciendo preguntas, es decir pidiendo a la gente en qué medida disfrutan de la vida como un todo. Las preguntas sobre la felicidad pueden plantearse en distintos contextos (entrevistas clínicas, cuestionarios de revisión de la vida o entrevistas en encuestas) y de distintas maneras (directa o indirectamente y por medio de preguntas simples o múltiples.

\section{Preguntas frecuentes}

Algunas de las preguntas más frecuentes se presentan en el siguiente cuadro.

\section{Dudas sobre la validez}

Algunos críticos han señalado que las respuestas a las preguntas sobre felicidad miden en realidad otros fenómenos. En lugar de indicar en qué medida el encuestado disfruta de la vida, las respuestas reflejan sus ideas normativas y sus deseos.

\section{Sin opinión}

Uno de los reparos es que la mayoría de las personas carecen de opinión sobre su felicidad. Son más conscientes de lo felices que se les supone y de eso es de lo que informan. Aunque pueda ocurrir ocasionalmente, esta no parece ser la regla. La mayoría de las personas saben muy bien si disfrutan de la vida o no. Ocho de cada diez estadounidenses piensan en ello todas las semanas. Las respuestas a las preguntas sobre felicidad tienden a ser rápidas. La falta de respuesta a estas preguntas es baja, tanto en sentido absoluto $( \pm 1 \%)$ como en relación a otras 
Cuadro 3. Algunas preguntas sobre felicidad que se utilizan actualmente

\section{Preguntas simples}

- Considerado globalmente, ¿en qué medida se considera feliz -muy feliz, bastante feliz no muy feliz, nada feliz? (tipo de pregunta utilizada en los World Value Studies - Encuesta Mundial sobre Valores).

- ¿En qué medida está satisfecho con la vida que lleva -muy satisfecho, bastante satisfecho, no muy satisfecho, nada satisfecho? (tipo de pregunta utilizada en las encuestas del Eurobarómetro).

- Observe el dibujo de la escalera. Imagine que el peldaño superior representa la mejor vida posible que Vd. puede llevar y el peldaño inferior la peor vida posible. ¿En qué tramo de la escalera se situaría $\mathrm{Vd}$. personalmente en la actualidad en una escala de 0 a10? (escalera de Cantril, 1965, de valoración de la vida actual).

\section{Preguntas múltiples (agregadas)}

- La misma pregunta hecha dos veces, al principio y al final de la entrevista: ¿cómo se siente en tu vida en general -encantado, contento, mayormente satisfecho, ni satisfecho ni insatisfecho, mayormente insatisfecho, infeliz, desgraciado? (Vida 3 - Andrews y Whitey, 1976).

- Cinco preguntas, a contestar en una escala de acuerdo de 1 a 7 , desde totalmente de acuerdo hasta totalmente en desacuerdo (Escala de Satisfacción con la Vida -SWLS, de Diener, 1985).

- En casi todos los sentidos mi vida es casi ideal.

- Las condiciones de mi vida son excelentes.

- Estoy satisfecho con mi vida.

- Hasta ahora he conseguido las cosas importantes que he deseado en la vida.

- Si volviera a empezar mi vida de nuevo, no cambiaría casi nada ${ }^{3}$. preguntas sobre actitudes. Las respuestas "no sé" son también infrecuentes.

Otra afirmación de este tipo es que los encuestados mezclan lo felices que son realmente en la actualidad con lo felices que los demás les consideran a la vista de su situación. Si esto fuera así, las personas a las que se considera acomodadas siempre dirían que son muy felices, mientras que aquellas a las que se considera desfavorecidas se catalogarían a sí mismas de infelices. A veces se observa esta pauta, pero no es general. Por ejemplo, en Holanda la buena educación se considera un requisito previo de una buena vida, pero las personas de educación superior parecen ligeramente menos felices que las menos educadas.

\section{Las respuestas en color}

Hay otra objeción a propósito de la presencia de un sesgo sistemático en las respuestas. Se supone que las preguntas sobre felicidad se interpretan correctamente, pero que las respuestas son a menudo falsas. Las personas que están realmente insatisfechas de la vida que llevan tenderían a contestar que son muy felices. Esta distorsión estaría producida tanto por la defensa del yo como por la deseabilidad social.

Este sesgo suele manifestarse en forma de exageración sobre la felicidad. La mayoría de las personas alegan que son felices y se ven más felices que la media. Otro indicio de la existencia del sesgo se aprecia en la observación de que las quejas psicosomáticas no son inusuales en las personas felices. No obstante, dichos hallazgos dan pie también a otras interpretaciones. En primer lugar, el hecho que haya más gente que diga que es feliz que la que se declara infeliz no implica exagerar sobre la felicidad. Es muy posible que la mayoría de la gente sea realmente feliz (algunos de los motivos se verán más adelante). En segundo lugar, hay también razones fundadas por las que la mayoría de las personas creen que son más felices que la media, una de las cuales es que las personas actúan como científicos críticos que piensan que la infelicidad es la regla. En tercer lugar, el hecho de que las personas felices padezcan dolores de cabeza y tengan preocupaciones no implica que distorsionen las respuestas. La vida puede ser a veces una dura prueba, pero el balance resulta ser satisfactorio.

La prueba del 9 es demostrar la distorsión de respuestas como tal. Determinados estudios clínicos lo han intentado comparando las respuestas a preguntas directas simples utilizando escalas sacadas de entrevistas en profundidad y tests proyectivos. Los resultados no son distintos que las respuestas a preguntas directas simples realizadas por un entrevistador anónimo.

\footnotetext{
3 En mi opinión este último ítem no es adecuado. Uno puede estar muy satisfecho en la vida y aún así estar abierto a la oportunidad de probar algo más.
} 


\section{Dudas sobre la fiabilidad}

Aunque las preguntas simples sobre la felicidad parezcan medir lo que se suponen que miden, dicha medida es bastante imprecisa.

Cuando en una entrevista se hace la misma pregunta dos veces, las respuestas no son siempre idénticas: la correlación es entorno a $+0,70$. La fiabilidad test-retest cae hasta cerca de $+0,60$ una semana después. Aunque las respuestas raramente cambian de "feliz" a "infeliz", es bastante habitual que cambien de "muy" a "bastante". La diferencia entre opciones de respuesta a menudo es ambigua. La idea que pueda tener un encuestado sobre su felicidad tiende a ser global, por lo que la elección de una categoría de respuesta o la siguiente se debe a veces al azar.

Ya que la elección es a menudo arbitraria, sutiles diferencias al preguntar pueden ejercer un efecto considerable. Cambios con respecto al lugar de la entrevista, características del entrevistador, el orden de las preguntas y la precisión en la formulación de las preguntas más importantes pueden inclinar la escala hacia una respuesta u otra. Estos efectos pueden darse en distintas fases del proceso de respuesta, tanto en la consideración de la respuesta como en su emisión.

\section{El sesgo en la valoración}

Aunque la mayoría de la gente tenga una idea de cuánto disfruta en la vida, responder a preguntas sobre el tema es algo más que rescatar de la memoria un juicio previo. En la mayoría de los casos el recuerdo sólo indica un intervalo de felicidad. Por lo general el asunto se reevalúa en un juicio instantáneo, reevaluación que puede limitarse a un cambio reciente (¿hay motivos para ser más o menos feliz que era?), pero también puede implicar una rápida reevaluación de la vida (¿qué ventajas y frustraciones tengo?). Al hacer dichos juicios instantáneos, la gente se sirve de distintos heurísticos. Estas simplificaciones mentales comportan errores concretos. Así, el heurístico de "disponibilidad" se refiere a la orientación hacia la información que está disponible de forma inmediata. Si el entrevistador está en una silla de ruedas la ventaja de tener buena salud cobra- rá relieve. Los entrevistados que tengan buena salud valorarán así algo más su felicidad y como resultado habrá una mayor correlación entre la valoración de la felicidad y las variables de salud. Schwarz y Strack (1991) demostraron varios de estos efectos heurísticos.

\section{Los sesgos en la respuesta}

Cuando un encuestado se ha formado un juicio particular el paso siguiente será expresarlo. En esta fase la información puede sufrir sesgos de distintos tipos también. Una fuente de sesgo es inherente a la semántica: los encuestados interpretan las palabras de distintas maneras y algunas de estas interpretaciones pueden verse influidas por preguntas anteriores. Por ejemplo, es más probable que las preguntas sobre felicidad se interpreten en el sentido de "satisfacción" cuando son precedidas de preguntas sobre el éxito en el trabajo en vez de preguntas sobre el estado de ánimo. Otra fuente de sesgo en las respuestas la encontramos en las consideraciones sobre la autopresentación y la deseabilidad social. La autovaloración de la felicidad tiende a ser ligeramente más elevada en las entrevistas personales que en cuestionarios anónimos. No obstante, el contacto con un entrevistador no siempre hincha la información sobre felicidad. Si el entrevistador está en silla de ruedas lo que se estimula es una auto-presentación modesta.

Muchos de estos sesgos se dan aleatoriamente, por lo que en grandes muestras se compensan. De este modo en muestras grandes el error aleatorio no afecta a la precisión de las medias de felicidad, aunque sí a las correlaciones: el error aleatorio "atenúa" las correlaciones. El error aleatorio puede estimarse mediante estudios múltirasgo-multimétodo (MR$\mathrm{MM})$, y las correlaciones corregirse (desatenuarse) sobre esa base. Saris et al. (1996) publicaron una primera aplicación de este método a las medidas de satisfacción.

Algunos sesgos pueden ser sistemáticos, en particular los producidos por la técnica de interrogación y por el orden de las preguntas. El sesgo de esa índole afecta a la fiabilidad de los datos de distribución. En principio no influye en las correlaciones salvo que esté sesgada, del mismo modo, la medida del 
correlato (error correlacionado). El error sistemático puede también estimarse y corregirse hasta cierto punto. Ver también Saris et al. (1996).

\section{Comparabilidad entre países}

La felicidad media difiere notablemente entre países. En el cuadro 5 podemos apreciar que los rusos puntúan 5,4 en una escala de 0 a 10 , mientras en Suecia la media es 7,7. ¿Significa que los rusos disfrutan menos de la vida? Se han propuesto algunos argumentos en sentido contrario. En otro trabajo he contrastado estas dudas (Ouweneel \&y Veenhoven, 1990; Veenhoven, 1993b), resumiendo los resultados a continuación.

La primera objeción es que las diferencias de lenguaje dificultan la comparación. Palabras como "felicidad" y "satisfacción" no tienen las mismas connotaciones en diferentes lenguas. Las preguntas formuladas mediante tales términos miden cuestiones ligeramente diferentes. Puse a prueba esta hipótesis comparando la jerarquización producida por tres tipos de preguntas sobre la satisfacción en la vida: una pregunta sobre "felicidad", otra sobre "satisfacción en la vida" y una tercera que invita a elegir entre "la mejor y la peor vida posible". La jerarquización resultó casi idéntica. Comparé también las respuestas a preguntas sobre felicidad y satisfacción en dos países bilingües y tampoco encontré pruebas de sesgo lingüístico.

La segunda objeción es que el sesgo de deseabilidad distorsiona las respuestas en distinto grado. En aquellos países en los que la felicidad tuviera un elevado valor la gente se inclinaría más a exagerar su disfrute de la vida. Verifiqué este extremo comprobando si la felicidad que se declaraba tener era realmente mayor en países en los que se tenía en mayor consideración los valores hedónicos. No parecía ser así. En una segunda comprobación traté de ver si la información sobre felicidad general se desviaba más de los sentimientos de las últimas semanas en estos países y la primera medida era más vulnerable a la distorsión de la deseabilidad que la última. Tampoco parecía ser así.

Una tercera afirmación es que los estilos de respuesta distorsionan las respuestas de modo distinto en diferentes países. Por ejemplo, la orientación colectivista desincentivaría las respuestas "muy feliz" porque la auto-presentación modesta fuera más adecuada en ese entorno cultural. Puse a prueba mi hipótesis comparando la felicidad en países que se diferenciaban en el valor colectivismo, pero no hallé efecto alguno en la dirección predicha. La hipótesis tampoco superó otras pruebas.

Otra afirmación en esta línea es que la felicidad es un típico concepto occidental y que su falta de familiaridad con él en los países no occidentales originaría puntuaciones más bajas. Si fuera así podríamos esperar más respuestas "no sé" y falta de respuesta en estos países, algo que no parecía ocurrir.

\section{Medidas de felicidad en distintos países}

Las preguntas sobre felicidad de las que acabamos de hablar se utilizan habitualmente en encuestas a la población general de distintos países. Un patrón típico de respuestas se ofrece en el cuadro 4. De estos datos pueden derivarse diversas medidas de felicidad.

\section{Felicidad media (average happiness)}

Los responsables públicos suelen estar interesados en la felicidad de la mayoría, lo cual se refleja en la tendencia central en las respuestas que puede expresarse en diversas estadísticas resumen como el porcentaje por encima de la respuesta neutra de la escala, la moda y la media. Esta última es la medida estadística utilizada con más frecuencia. La felicidad media se expresa a menudo en un rango de 0 a 10 , lo cual invita a una interpretación del tipo de las "notas académicas".

\section{Años de Vida Feliz (Happy Life Years)}

Los políticos aspiran en general a la felicidad duradera, lo que concuerda con la recomendación de Bentham de calcular la felicidad teniendo en cuenta no sólo su intensidad sino su duración. Una de las maneras de lograrlo es combinar la informa- 


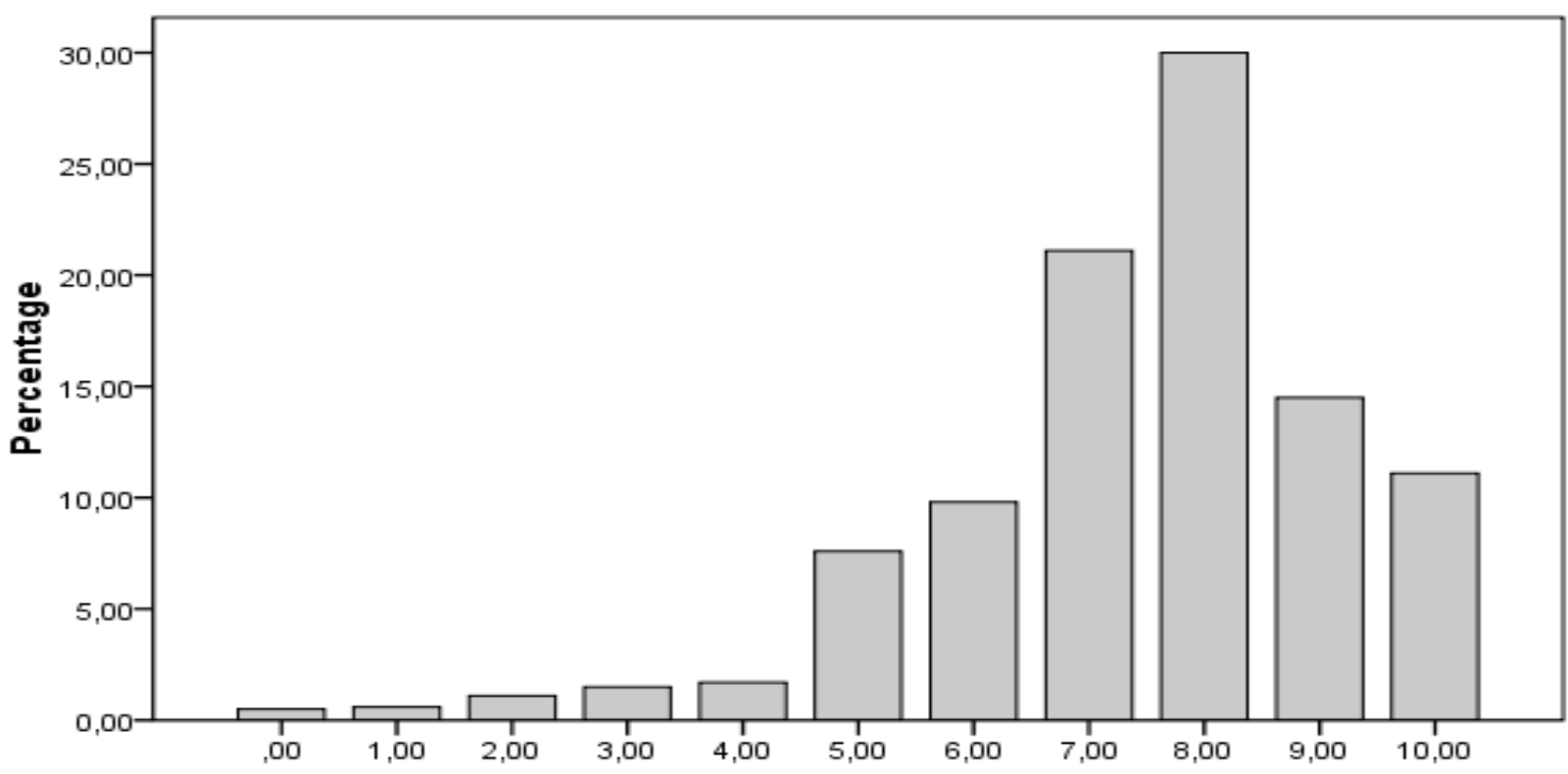

Happiness in Spain

Fuente: Encuesta Social Europea 2006

ción sobre la vida, procedente de los registros civiles de nacimiento y fallecimiento ${ }^{4}$, con datos sobre la valoración media de la vida tal y como se evalúa en las encuestas.

\section{Cálculo}

Puede aplicarse la siguiente fórmula:

\section{Años de vida feliz $=$ Esperanza de vida al nacer $x$ felicidad 0-1}

Imagine que la esperanza de la vida en un país determinado es de 60 años y que la puntuación media en la escala de felicidad de 0 a 10 pasos es de 5. Convertida a una escala de 0-1 la puntuación en felicidad será así 0,5 . El producto de 60 por 0,5 es 30. De este modo el número de años de vida feliz es 30 en dicho país. Si la esperanza de vida fuera también de 60 años pero la felicidad media fuera 8 , el

\footnotetext{
${ }^{4}$ El registro civil es una fuente de información sobre la longevidad de los ciudadanos que han muerto. A partir de ahí se calcula la esperanza de vida de los ciudadanos vivos, estimaciones que denotan el cambio en las condiciones de vida y avances en sanidad.
}

número de años de vida feliz sería $48(60$ x 0,8).

\section{Ventajas}

Esta combinación de felicidad y longevidad tiene la ventaja añadida de aportar un cuadro más completo sobre cómo prospera la gente en un país determinado. En los animales inferiores una buena adaptación tiene su reflejo sólo en la supervivencia, mientras que en los animales superiores también se refleja en la experiencia hedónica. El afecto negativo es indicador de una mala adaptación y funciona como una señal de "siga". Por eso, si un animal no se siente bien probablemente no le vaya bien. Esta experiencia interna no tiene mayor importancia en biología dado que no podemos valorar cómo se siente un animal. Los seres humanos pueden reflexionar sobre su experiencia y condensar los afectos positivos y negativos en una valoración global de la felicidad. También son capaces de transmitir esa valoración a los investigadores. Así, en el caso de los seres humanos podemos utilizar la buena adaptación como indicador adicional, y evaluar cuánto viven y lo felices que viven. 
Otra ventaja de esta combinación es que se adecua al sentido común: preferimos una vida larga y feliz a una breve aunque feliz o a una larga pero infeliz. Otra ventaja es que esta medida se relaciona con otra meta de las políticas públicas más consolidada y es comparable al índice DALY ${ }^{5}$. Esto explica por qué los años de vida feliz obtenían las puntuaciones más elevadas en una revisión de indicadores de calidad de vida en distintos países hecha por expertos (Hagerty et al., 2001).

\section{Desigualdad en felicidad (Inequality of Happiness)}

Una felicidad media elevada puede ir de la mano de una considerable desigualdad en felicidad: la mayoría es muy feliz a costa de una minoría infeliz. La mayoría de los políticos verían esto como indeseable, dado que la igualdad social tiene una consideración alta en la agenda política. Por tanto, también hay demanda de información sobre la disparidad en felicidad en los países, comparable a los datos sobre desigualdad en renta y salud.

En este caso el foco de atención no es la tendencia central de la distribución de las respuestas a las preguntas sobre desigualdad como muestra el cuadro 4, sino la disparidad de la distribución, que de

5 Años de Vida Ajustados a la Discapacidad, esperanza de vida corregida por los años de mala salud. La medida la utiliza la Organización Mundial de la Salud. nuevo puede expresarse en diversas estadísticas sintéticas, como la desviación típica, el rango intercuartil y el coeficiente de Gini. Un análisis comparativo mostró que la desigualdad en felicidad puede cuantificarse mejor utilizando la desviación típica y que el coeficiente de Gini no es adecuado para este tipo de datos (Kalmijn y Veenhoven 2006).

\section{Felicidad Ajustada a la Desigualdad (Inequality Adjusted Happiness = IAH)}

Los políticos se propondrán, en general, el logro de un nivel elevado de felicidad y un grado bajo de desigualdad en felicidad. Por este motivo necesitan un indicador que case el deseo utilitario de mayor felicidad con la exigencia igualitaria de justicia. Tal indicador es el índice de "felicidad ajustada a la desigualdad", que asigna un peso igual a ambos objetivos (Veenhoven \&y Kalmijn 2006).

\section{Grado de felicidad en distintos países}

Los datos procedentes de encuestas se recopilan en la Base de Datos Mundial sobre Felicidad (Veenhoven, 2009). En este momento dicha fuente dispone de datos comparables de 144 países sobre los cuatro indicadores que se presentan en los denominados "informes de resultados" (Veenhoven, 2009a-d). En el cuadro 5 se ofrecen algunos datos ilustrativos.

\begin{tabular}{|c|c|c|c|c|}
\hline \multicolumn{5}{|c|}{ Cuadro 5 . La felicidad en los países, alrededor de 2006} \\
\hline País & $\begin{array}{c}\text { Felicidad } \\
\text { media } \\
\text { escala de } \\
0-10\end{array}$ & $\begin{array}{c}\text { Años de vida feliz } \\
\text { esperanza de vida } \\
\text { multiplicada por } \\
\text { felicidad } 0-1\end{array}$ & $\begin{array}{c}\text { Desigualdad } \\
\text { desviación típica } \\
\text { en escala } 0-10\end{array}$ & $\begin{array}{c}\text { Felicidad } \\
\text { ajustada a la } \\
\text { desigualdad } \\
\text { indice } 0-100 \\
\end{array}$ \\
\hline Dinamarca & 8,4 & 65,5 & 2,0 & 77 \\
\hline México & 8,0 & 60,3 & 2,5 & 71 \\
\hline Suecia & 7,7 & 62,2 & 1,9 & 70 \\
\hline España & 7,2 & 57,8 & 1,9 & 66 \\
\hline EEUU & 7,0 & 54,7 & 2,0 & 63 \\
\hline Francia & 6,5 & 52,0 & 2,2 & 58 \\
\hline Filipinas & 6,3 & 44,7 & 2,8 & 53 \\
\hline Portugal & 5,7 & 44,0 & 2,2 & 50 \\
\hline Marruecos & 5,2 & 36,4 & 2,4 & 44 \\
\hline Rusia & 5,4 & 35,3 & 2,8 & 45 \\
\hline Irak & 4,3 & 28,6 & 2,7 & 35 \\
\hline Zimbabwe & 3,3 & 13,5 & 3,0 & 24 \\
\hline
\end{tabular}

Fuente: World Database of Happiness. Happiness in Nations (Veenhoven 2009a, 2009b, 2009c, 2009d). 


\section{La Felicidad Media (FM)}

El cuadro 5 presenta la felicidad media en distintos países en una escala de 0 a 10 . La puntuación más elevada se observa en Dinamarca $(8,4)$ y la más baja en Zimbabwe $(3,3)$, siendo la variación real en este rango de 5 puntos. La felicidad media está por encima del punto medio de la escala (neutro), lo cual significa que parece posible una gran felicidad para un gran porcentaje de población. Sin embargo hay países cuya media está por debajo de 5 , uno de los cuales es un país castigado por la guerra como Irak. La felicidad media es aún inferior en varios países africanos.

\section{Años de Vida Feliz (AVF)}

En teoría AVF, indicador sujeto a una gran variación, es cero si nadie puede vivir en el país y sería infinito si la sociedad es ideal y sus habitantes inmortales. El rango práctico se encuentra actualmente en los 50 años, el mayor número de años de vida feliz lo tiene Dinamarca $(65,5)$ y el menor Zimbabwe $(13,5)$.

La ordenación por rango de la AVF es bastante parecido al de la felicidad media, siendo la correlación de rangos $+0,94$. Dicha correlación no es sin embargo, perfecta dado que en algunos países la gente vive mucho tiempo pero no son demasiado felices (como ocurre con Japón), mientras que en otros la vida es breve pero bastante satisfactoria (por ejemplo en Nigeria). La correlación de rangos entre esperanza de vida y Felicidad Media es de +0,55.

\section{Desigualdad en Felicidad (DF)}

El menor grado de desigualdad se observa en Suecia y España $(\mathrm{DT}=1,9)$ y el mayor en Zimbabwe $(3,0)$. Una vez más, la ordenación por rango es similar a la de la Felicidad Media (rs = $0,65)$.

\section{Felicidad Ajustada a la Desigualdad (FAD)}

La variación en este índice de 0 a 100 está entre el 77 de Dinamarca y el 24 de Zimbabwe. La orde- nación por rangos de los países es de nuevo similar a la de la Felicidad Media $(r=+0,95)$.

\section{Tendencias de la felicidad en distintos países}

Sólo hay datos comparables de 25 años o más para 11 de los 144 países de la Base de Datos Mundial sobre Felicidad. Dichos países son EEUU desde 1945, Japón desde 1958 y los 9 primeros Estados miembros de la Unión Europea desde $1973^{6}$. Estos datos se hallan disponibles en el fichero de datos "TrendsInNations", que forma parte de dicha Base de datos (Veenhoven, 2009e).

\section{Incremento gradual de la Felicidad Media en la mayoría de los países}

Los datos sobre la tendencia de la felicidad media se presentan en el cuadro 6 , donde se ve que la felicidad ha aumentado algo en EEUU y en la UE9, pero se han estancado en Japón.

El aumento que se observa en EEUU contradice la opinión actual de que los estadounidenses son más ricos pero no más felices. Este fenómeno, denominado "paradoja de Easterlin", se mantiene en el discurso económico sobre felicidad pero no se ajusta a los últimos datos (Veenhoven y Hagerty, 2006). Este trabajo presenta datos que indican que la felicidad ha aumentado en varios países desarrollados.

\section{Aumento espectacular de los Años de Vida Feliz}

La esperanza de vida ha crecido igualmente en el último decenio, por lo que no debe sorprender que haya aumentado también el número de años de vida feliz, como se ve en el cuadro 7. Sin embargo, resulta sorprendente ver que los cambios sean tan grandes: 7,2 años en la UE entre 1973 y 2008 y 4,2 en EEUU en el mismo periodo. Más detalles sobre este aumento en la calidad de vida aparente pueden encontrarse en otro trabajo (Veenhoven, 2005a). ¡Este crecimiento en años de vida feliz no tiene pre-

\footnotetext{
6 Bélgica, Dinamarca, Francia, Alemania (Federal), Luxemburgo, Italia, Holanda y Reino Unido.
} 
Cuadro 6. Tendencia en la felicidad media en la UE9, Japón y EEUU

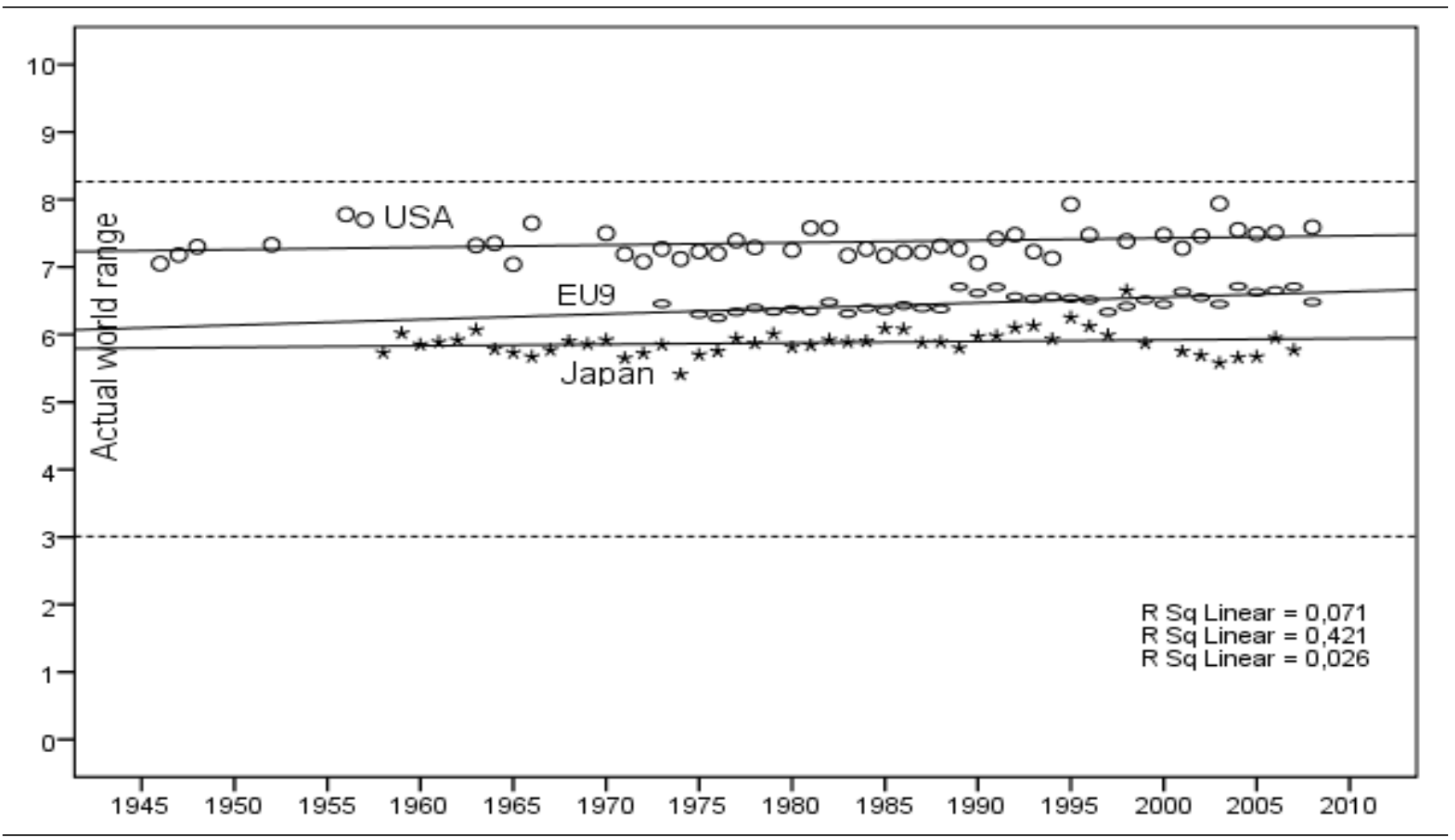

Fuente: World Database of Happiness. Happiness in Nations; archivo de datos Trend in Nations (Veenhoven, 2009f).

Cuadro 7. Tendencia en los años de vida feliz en la UE9, Japón y EEUU

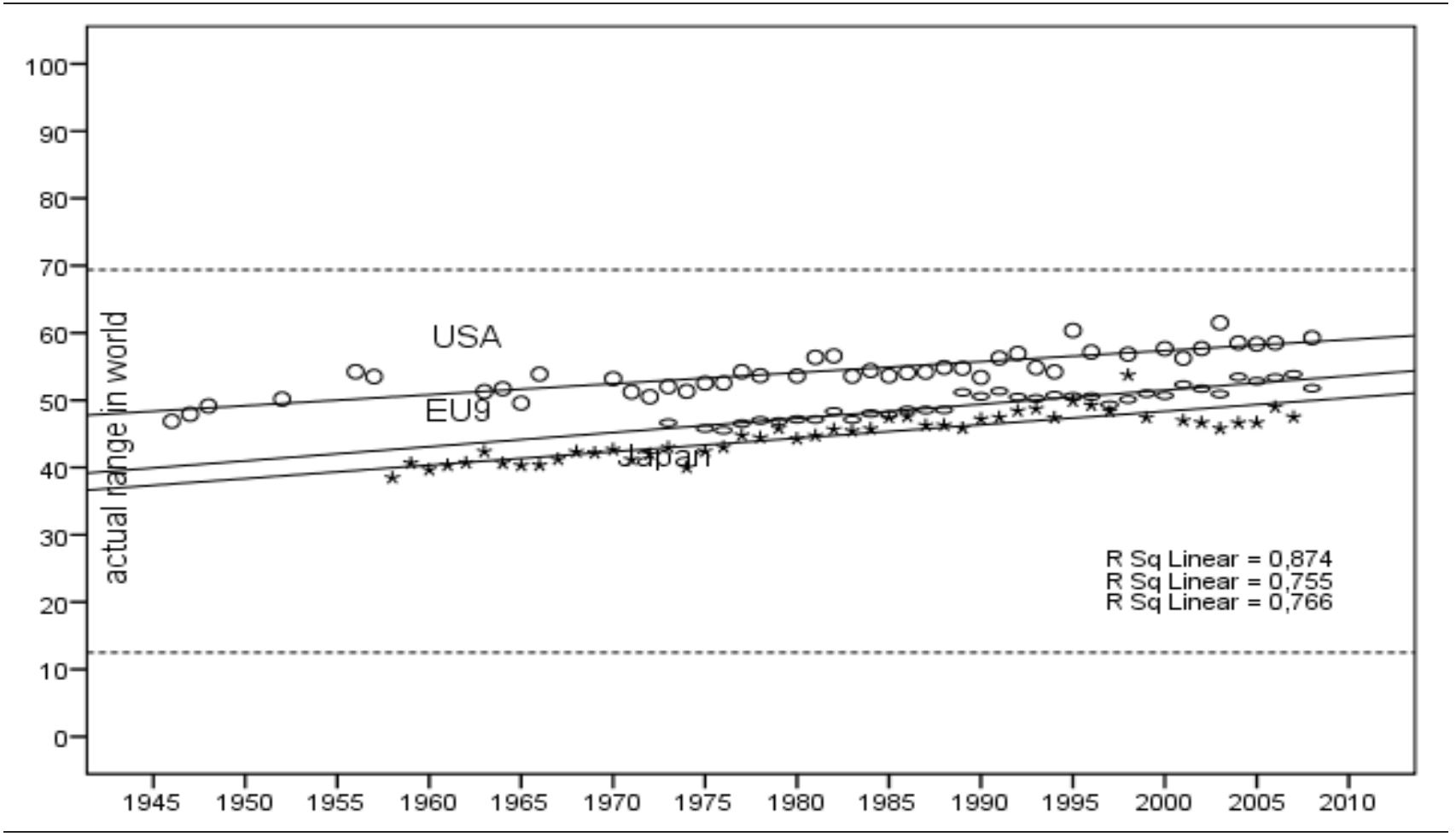

Fuente: World Database of Happiness. Happiness in Nations; archivo de datos "Trend in Nations" (Veenhoven, 2009f). 
Cuadro 8. Tendencias en la dispersión de la satisfacción vital en la UE9, Japón y EEUU

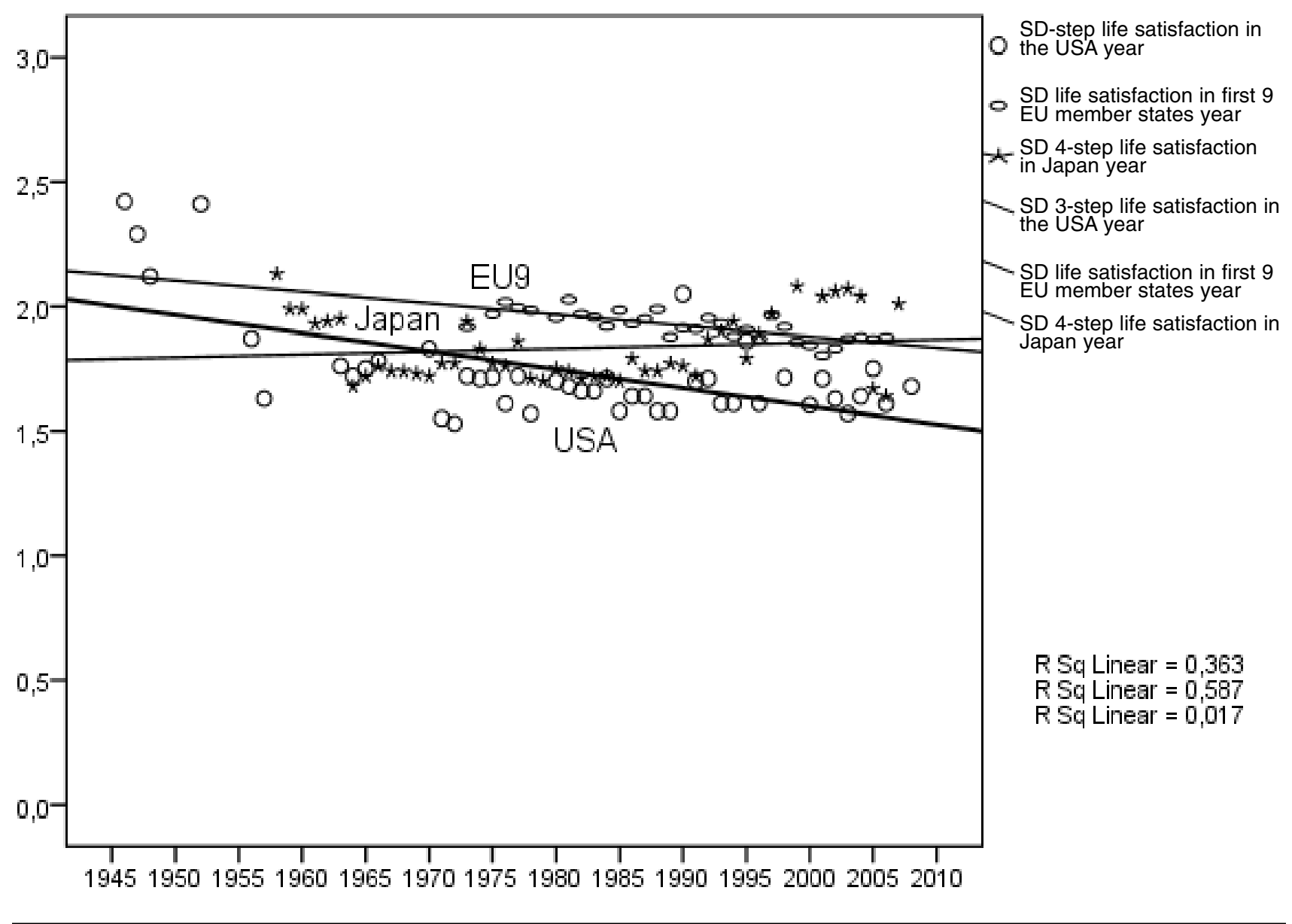

Fuente: World Database of Happiness. Happiness in Nations; archivo de datos "Trend in Nations" (Veenhoven, 2009f).

cedentes en la historia de la humanidad y denota un progreso social considerable!

\section{Reducción de la Desigualdad en Felicidad en dis- tintos países}

Preocupan mucho las "nuevas desigualdades" que aparecen en los países modernos, a pesar de que los datos de dispersión de la felicidad muestren más bien un patrón de desigualdad decreciente. En el cuadro 8 vemos que la desigualdad en felicidad se mantiene prácticamente en el mismo nivel en Japón aunque desciende en los primeros 9 Estados de la UE y en EEUU, resultados que se discuten con mayor detalle en otro trabajo (Veenhoven, 2005b).

\section{Aumento de la Felicidad Ajustada a la Desigualdad}

$\mathrm{Al}$ aumentar la media de felicidad y descender la desigualdad en felicidad, no sorprende que haya subido el índice de Felicidad Ajustada a la Desigualdad (FAD). En EEUU el aumento ha sido de 3,5 puntos en la escala de 0 a 100 y de 3,2 puntos en la UE.

\section{Determinantes de la felicidad en distintos países}

Hasta ahora los datos muestran que la felicidad es una meta realista en las políticas públicas. Parece posible que la felicidad alcance a la mayoría, ya que la mayoría de las personas valoran la felicidad por 
encima del punto medio de la escala (neutro) en la mayoría de países. También es posible mayor felicidad en gran parte de los países del mundo. Lo que es posible en países como Dinamarca también debería ser posible en cualquier otro.

\section{Correlatos societales de la felicidad}

Esto suscita la pregunta de cuáles son las mejores políticas para lograr felicidad, lo que supone explicar cuáles son los determinantes de la felicidad en los distintos países. Habría para ello que comparar los países cuyos habitantes son más felices con aquellos cuyos ciudadanos son menos felices. Es una línea emergente de investigación cuyos resultados se almacenan igualmente en la Base de Datos Mundial sobre Felicidad, en la sección de "Correlational Findings”, en la categoría temática N4, “nation's condition". El cuadro 9 ofrece una panorámica general ilustrativa.

\section{Prosperidad material}

En el cuadro 9 vemos que la felicidad media suele ser elevada en los países más prósperos económicamente: mientras más rico es el país más felices son sus habitantes. En los indicadores que se obtienen sobre felicidad aparecen relaciones similares, correlaciones positivas con los Años de Vida Feliz y con la Felicidad Ajustada a la Desigualdad y negativas con la Desigualdad en Felicidad. El efecto de la prosperidad económica puede explicarse en parte por el efecto que produce sobre la prevalencia de pobreza absoluta, si bien los datos indican que esto no es todo. Evidentemente el bienestar material es más gratificante que la mera subsistencia.

Cuadro 9. Felicidad y sociedad: 135 países en torno a 2006

\begin{tabular}{|c|c|c|c|c|}
\hline \multirow[b]{2}{*}{ Situación en el país } & \multicolumn{4}{|c|}{ Correlación con } \\
\hline & $\begin{array}{l}\text { Felicidad } \\
\text { Media }\end{array}$ & $\begin{array}{l}\text { Desigualdad en } \\
\text { Felicidad }\end{array}$ & $\begin{array}{c}\text { Felicidad } \\
\text { Ajustada a } \\
\text { la Desigualdad }\end{array}$ & $\begin{array}{c}\text { Años de Vida } \\
\text { Feliz }\end{array}$ \\
\hline \multicolumn{5}{|l|}{ Riqueza } \\
\hline - Poder adquisitivo p.c. & $+0,69$ & $-0,52$ & $+0,67$ & $+0,77$ \\
\hline \multicolumn{5}{|l|}{ Seguridad } \\
\hline - Accidentes mortales & $-0,39$ & $+0,42$ & $-0,44$ & $-0,42$ \\
\hline - Seguridad social & $+0,39$ & $-0,47$ & $+0,37$ & $+0,52$ \\
\hline \multicolumn{5}{|l|}{ Libertad } \\
\hline - Libertad económica & $+0,63$ & $-0,46$ & $+0,62$ & $+0,67$ \\
\hline - Libertad política & $+0,53$ & $-0,27$ & $+0,52$ & $+0,56$ \\
\hline - Libertad personal & $+0,41$ & $-0,46$ & $+0,44$ & $+0,52$ \\
\hline \multicolumn{5}{|l|}{ Desigualdad } \\
\hline - Disparidad en renta & $+0,08$ & $+0,21$ & $-0,06$ & $-0,26$ \\
\hline - Discriminación de la mujer & $-0,21$ & $+0,00$ & $-0,19$ & $-0,28$ \\
\hline \multicolumn{5}{|l|}{ Fraternidad } \\
\hline - Tolerancia & $+0,49$ & $-0,35$ & $+0,49$ & $+0,45$ \\
\hline - Confianza en las personas & $+0,39$ & $-0,45$ & $+0,43$ & $+0,44$ \\
\hline • Educación & $+0,56$ & $-0,15$ & $+0,53$ & $+0,70$ \\
\hline Trabajo voluntario & $-0,04$ & $+0,24$ & $-0,09$ & $-0,16$ \\
\hline \multicolumn{5}{|l|}{ Justicia } \\
\hline - Imperio de la leyEstado de derecho ("rule of law") & $+0,66$ & $-0,49$ & $+0,67$ & $+0,75$ \\
\hline - Respeto a los derechos civiles & $+0,50$ & $-0,28$ & $+0,49$ & $+0,56$ \\
\hline - Corrupción & $-0,69$ & $+0,51$ & $-0,69$ & $-0,76$ \\
\hline Varianza explicada: $\mathrm{R}^{2}$ ajustada & $77 \%$ & $58 \%$ & $65 \%$ & $92 \%$ \\
\hline
\end{tabular}

Datos: World Database of Happiness. State of Nations (Veenhoven 2009e). Los indicadores se describen en el apéndice. 


\section{Seguridad}

También la felicidad es mayor en los países que brindan más seguridad. En el cuadro 9 hay mayor correlación con la incidencia de accidentes mortales, que es indicativa de una seguridad física más amplia. El patrón de correlaciones es de nuevo similar en los cuatro indicadores de Felicidad Nacional Bruta. Esta relación parece en gran medida independiente de la prosperidad económica. La relación con la seguridad social que brinda el estado es menor, aunque hay una correlación positiva con los gastos para los subsidios por discapacidad y desempleo, y con las pensiones para los ancianos, que desaparece cuando se controla la prosperidad económica (Veenhoven, 2000b).

\section{Libertad}

La gente es más feliz también en países que permiten mayor autonomía. En el cuadro 9 se aprecia una fuerte relación con los indicadores de libertad política, en gran medida independientes de la prosperidad económica. Las correlaciones con los indicadores de libertad personal son más bajas pero positivas todas. Una vez más, los cuatro indicadores de Felicidad Nacional Bruta se comportan de un modo parecido.

La libertad en la sociedad puede influir en la felicidad de los ciudadanos de varias maneras: es probable que la libertad política proteja contra la injusticia y la agresión y la libertad personal puede permitir que la gente elija el estilo de vida que mejor se ajuste a sus necesidades y capacidades. Probablemente ambos efectos conllevan hechos más reforzantes. La oportunidad de elegir aporta felicidad sólo en aquellas sociedades cuya capacidad de elección está muy desarrollada (Veenhoven, 2000a).

\section{Igualdad}

Parece bastante evidente que la gente es más feliz en sociedades más igualitarias y en las que hay menores diferencias en felicidad. Pero esto mismo no parece ocurrir con la desigualdad en la renta que básicamente no guarda relación con la felicidad media de los ciudadanos y apenas con la desigual- dad en felicidad entre ellos. Ott (2005) y Berg (2007) abordan la posible explicación de este resultado contraintuitivo. Los resultados concuerdan más con el sentido común cuando se trata de la desigualdad de género. La felicidad es sistemáticamente menor en países en los que se discrimina a la mujer, correlación que disminuye mucho cuando "se controla” la riqueza del país (Chi Hon Foei, 2007).

La desigualdad social puede influir negativamente en la felicidad, por las frustraciones y limitaciones que conlleva. Posiblemente algunos tipos de desigualdad conlleven efectos positivos que compensen los negativos, como puede ocurrir con la relación entre renta y desigualdad.

\section{Hermandad}

Suele creerse que la gente es más feliz en un clima de fraternidad y que en esas condiciones disminuirán las diferencias en felicidad. Esta creencia se ve confirmada por las correlaciones con "tolerancia" y "confianza en las personas", que suelen ser notables y, en gran medida, independientes de la riqueza del país. Sorprendentemente no hay correlación con el "trabajo voluntario".

\section{Justicia}

Por último, hay motivos suficientes para esperar que la justicia social mejore el nivel de felicidad en un país y disminuya las desigualdades. Dicha expectativa la corroboran las altas y sólidas correlaciones con las variables "Estado de Derecho", "respeto a los derechos civiles" y la falta de corrupción. Cuando se "controla" la riqueza del país desaparece gran parte de la correlación, pero debemos ser conscientes de que esto no significa que los efectos reales sean despreciables.

\section{Varianza explicada}

Introdujimos todas las variables en una regresión, con la excepción de los accidentes mortales, seguridad social y libertad personal ante los pocos casos con los que se contaba. 
En conjunto estas seis cualidades societales explican el 77\% de las diferencias en Felicidad Media, el $58 \%$ de las diferencias en Desigualdad en Felicidad, el $65 \%$ en Felicidad Ajustada a la Desigualdad y no menos del 92\% de las diferencias en Años de Vida Feliz.

\section{Congruencia entre las medidas de felicidad}

Las medidas de felicidad que aparecen en este artículo se ajustan a objetivos políticos matizadamente distintos. La Felicidad Media es una medida adecuada para las políticas encaminadas al logro de mayor felicidad para un mayor número de personas, aunque las mejoras en esta medida podrían ser pasajeras. Por ello es más adecuada la medida de Años de Vida Feliz para políticas dirigidas a lograr una felicidad duradera, como también es la medida más sensible a las condiciones que pueden verse afectadas por la política social (cfr. varianza explicada en el cuadro 9). La medida de Desigualdad en Felicidad está diseñada para políticas que persiguen la justicia en primer lugar, y el índice de Felicidad Ajustada a la Desigualdad está pensado para políticas con el doble propósito.

Las correlaciones del cuadro 9 nos documentan sobre la compatibilidad de estos objetivos de las políticas. La divergencia en las correlaciones denota incompatibilidad: por ejemplo si la prosperidad económica correlacionara más con la Felicidad Media que con los Años de Vida Feliz. Un repaso a los datos desde esta perspectiva nos lleva a concluir que a la mayoría de los objetivos se llega con los mismos medios. Por ejemplo, las políticas encaminadas a una mayor seguridad física parecen contribuir a la Felicidad Media y a los Años de Vida Feliz, a la vez que reducen la Desigualdad en Felicidad.

Hay un solo caso de divergencia en el cuadro 9: la desigualdad de renta entre países no se asocia a menores niveles de felicidad, pero sí a una mayor Desigualdad en Felicidad.

\section{Conclusión}

La felicidad se entiende como el disfrute subjeti- vo de la vida como un todo. Ya que esto es algo que la gente piensa, puede medirse mediante preguntas directas en encuestas a gran escala aplicadas a la población general.

A partir de las respuestas se pueden extraer cuatro medidas de felicidad en los distintos países: 1) Felicidad Media, 2) Años de Vida Feliz, 3) Desigualdad en Felicidad y 4) Felicidad Ajustada a la Desigualdad. Las cuatro medidas revelan grandes diferencias entre países y mejoras considerables a lo largo del tiempo. La pauta de correlación con una serie de características societales es muy similar.

Los resultados obtenidos utilizando estas medidas muestran que la felicidad es un objetivo realista para las políticas públicas. La felicidad de la mayoría parece posible en la sociedad moderna, así como una mayor felicidad. Lo que está menos claro es cómo puede lograrse esto. Los datos disponibles señalan que la mayoría de las mejoras pueden lograrse mediante políticas que se centren en la libertad y la justicia. No parece probable que el crecimiento económico añada mucha felicidad en los países prósperos, como tampoco la reducción de las diferencias en renta o una mejor seguridad social.

\section{Referencias}

Andrews, F. M. y Withey, S. B. (1976). Social indicators of well-being. New York, U.S.A.: Plenum Press.

Bentham, J. (1789). An introduction into the principles of morals and legislation. London.

Berg, M (2007)Inkomensongelijkheid en geluk in landen (Inequality in income and happiness in nations) Mens en maatschappij, 82, 28-50

Cantril, H. (1965). The pattern of human concern. New Brunswick, NJ: Rutgers University Press.

ChinHonFoei, S. (2006). Gender equality and Happiness in nations Paper presented at Dag van de Sociologie, Tilburg 8-6-2006

Diener, E., Emmons, R. A., Larsen, R. J. y Griffin, S. (1985). The satisfaction with life scale, Journal of Personality Assessment, 49, 71-75.

Donovan, N. Halpern, D. y Sergeant, R. (2003). Life Satisfaction: The State of Knowledge and Implications for Government. Discussion Paper, 
Strategy Unit, Government UK psychology'. New

York: Russell Sage Foundation.

Hagerty Hagerty, Michael R.; Vogel, Joachim; Møller, Valerie (Eds.) (2002). Assessing Quality of Life and Living Conditions to Guide National Policy; The State of the Art Springer: Social Indicators Research Series, Vol. 11.

Kalmijn, W. M. y Veenhoven, R. (2006). Measuring inequality of happiness in nations: In search for proper statistics. Journal of Happiness Studies, Special issue on 'Inequality of Happiness in Nations', 6, 357-396.

Lane, R. E. (1994). Quality of life and quality of persons: A new role for government? Political theory, 22, 219-252.

Lawton, M. P. (1975). Philadelphia geriatric center morale scale-revision, Journal of Gerontology, $30,85-89$.

Ott, J. (2005). Level and equality of happiness in nations: Does greater happiness for a greater number imply greater inequality in happiness? Journal of Happiness Studies, 6, 397-420.

Ouweneel, P. y Veenhoven, R. (1990). CrossNational Differences in Happiness: Cultural Bias or Societal Quality? En N. Bleichrodt, P.J. Drenth (Eds.), Contemporary Issues in Cross Cultural Psychology, Swets y Zeitlinger, 1990/91, Netherlands: Lisse.

Saris, W. E., Scherpenzeel, A.C. y VanWijk, T. (1998). Validity and Reliability of Subjective Social Indicators. Social Indicators Research, 45, 173-199.

Schwarz, N. y Strack, F. (1991). Evaluating One's Life: A Judgment Model of Subjective WellBeing in F. Strack et al (Eds.), Subjective WellBeing, (pp. 27-47). Oxford, UK: Pergamon.

Sen, A. (1992). Capability and wellbeing, In: A. Sen, y M. Nussbaum (Eds.), The quality of life, (pp. 30-53 ). Oxford, UK: Clarendon Press.

Veenhoven, R. (1991). Is happiness relative?. Social Indicators Research, 24, 1-34.

Veenhoven, R. (1993). Happiness in nations: Subjective appreciation of life in 56 nations 19461992 RISBO. Netherlands: Erasmus University Rotterdam.

Veenhoven, R. (1994). El Estudio de la satisfacción con la vida. Intervención Psicosocial, 3, 87-116.
Veenhoven, R. (2000a). Freedom and happiness: a comparative study in 44 nations in the early 1990's Published in: E. Diener y E.M. Suh, (eds), Culture and subjective wellbeing, (257-288). MA USA: MIT press,Cambridge.

Veenhoven, R. (2000b). Wellbeing in the welfare state: Level not higher, distribution not more equitable Journal of Comparative Policy Analysis, 2, 91-125.

Veenhoven, R. (2000c). The four qualities of life, Journal of Happiness Studies, 1, 1-39.

Veenhoven, R. (2005a). Is life getting better? How long and happy do people live in modern society? Published in: European Psychologist, 2005, special section on 'Human development and Wellbeing', 10, 330-343.

Veenhoven, R. (2005b). Return of inequality in modern society? Test by trend in dispersion of life-satisfaction across time and nations. Journal of Happiness Studies, Special issue on Inequality of Happiness in Nations', 6, 457-487

Veenhoven, R. (2008a). How do we assess how happy we are? In: A. Dutty y B. Radcliff (eds). Happiness, Economics and Politics. USA: Edward Elger Punlishers.

Veenhoven, R. (2008b). Healthy happiness: Effects of happiness on physical health and the consequences for preventive health care. Journal of Happiness Studies, 9, 449-464.

Veenhoven, R. (2009). World Database of Happiness: Continuous register of scientific research on subjective enjoyment of life. Netherlands: Erasmus University Rotterdam, Available at: http://worlddatabaseofhappiness.eur.nl.

Veenhoven, R. (2009a). Trend Average Happiness in nations 1946-2008. World Database of Happiness, Trend report 2009-1. Available at: http:// worlddatabaseofhappiness.eur.nl/hap_nat/findingreports/list_of_reports.htm.

Veenhoven, R. (2009b). Trend Happy Life Years in nations 1946-2008. World Database of Happiness, Happiness in nations, Trend report 2009-2, Available at: http://worlddatabaseofhappiness.eur.nl/hap_nat/findingreports/list_of_repor ts.htm.

Veenhoven, R. (2009c). Trend Inequality of happiness in nations 1946-2008. World Database of Happi- 
ness, Happiness in nations, Trend report 2009-3 Available at: http://worlddatabaseofhappiness. eur.n/hap_nat/findingreports/list_of_reports.htm

Veenhoven, R. (2009d). Trend Inequality-Adjusted Happiness in nations 1946-2004. World Database of Happiness, Happiness in nations, Trend report 2009-4, Available at: http://worlddatabaseofhappiness.eur.nl/hap_nat/findingreports/list_of_repor ts.htm
Veenhoven, R. (2009e). States of nations: Data set to be used for the cross-national analysis of happiness Code book available at: http://worlddatabaseofhappiness.eur.nl/statnat/statnat_fp.htm

Veenhoven, R. \& Hagerty, M (2006). Rising happiness in nations,1946-2004. A reply to Easterlin Social Indicators Research, 79, 421-436, DOI 10.1007/s11205-005-5074-x World Database of Happiness See Veenhoven 2006.

Manuscrito recibido: 14/09/2009

Revisión recibida: 29/09/2009

Manuscrito aceptado: 01/10/2009

APÉNDICE

Variables utilizadas en el Cuadro 9

\begin{tabular}{|c|c|c|c|}
\hline Nombre de la variable & Código de la variable & Descripción & $\mathbf{N}$ \\
\hline Felicidad Media & Happiness LSBW10.11_2000.08 & $\begin{array}{l}\text { Satisfacción vital en } 10+11 \text { peldaños, complementada } \\
\text { con estimaciones en una escala de } 11 \text { peldaños } \\
\text { (mejor-peor) }\end{array}$ & 146 \\
\hline Desigualdad en Felicidad & SD HappinessLSBW10.11_2000.08 & $\begin{array}{l}\text { Desviación típica de la satisfacción vital en 10+11 } \\
\text { peldaños, complementada con estimaciones en una } \\
\text { escala de } 11 \text { peldaños (mejor-peor) }\end{array}$ & 136 \\
\hline Felicidad Ajustada a la Desigualdad & IAH_2000_2006 & $\begin{array}{l}\text { Combinación de la media y desviación típica de la } \\
\text { felicidad }\end{array}$ & 133 \\
\hline Años de Vida Feliz & HLY_LSBW10.11_2000.08 & Promedio de años de vida feliz & 145 \\
\hline Poder adquisitivo per cápita & RGPD_2005 & $\begin{array}{l}\text { Producto Nacional Bruto real (expresado en poder ad- } \\
\text { quisitivo) }\end{array}$ & 166 \\
\hline Accidentes mortales & AcceidentDeaths_1994.98 & Accidentes mortales por 100.000 . Registros sanitarios & 67 \\
\hline Seguridad social & WelfareExpense2b_2004 & Gastos sociales públicos en $\%$ de PNB & 57 \\
\hline Libertad económica & FreeEconIndex2_2007 & Índice de Libertad económica & 155 \\
\hline Derechos políticos & PoliticalRights_2004 & Supresión de derechos políticos (escala invertida) & 133 \\
\hline Libertad personal & PrivateFreedom_1999s & Índice de Libertad privada & 86 \\
\hline Desigualdad de renta & IncomeInequality1_2005 & Desigualdad en la renta (gini) & 126 \\
\hline Discriminación de la mujer & GenderInstitutionsIndex_1990s & $\begin{array}{l}\text { Índice de discriminación de la mujer en instituciones } \\
\text { sociales }\end{array}$ & 123 \\
\hline Tolerancia & Tolerance_1999 & $\begin{array}{l}\text { Aceptación como vecinos de personas pertenecientes a } \\
\text { minorías }\end{array}$ & 78 \\
\hline Confianza en la gente & TrustPeople_1990s2 & Confianza en las personas & 85 \\
\hline Educación & EducationIndex 2.2000 .04 & $\begin{array}{l}\text { Índice de educación (alfabetización + matriculación es- } \\
\text { colar) }\end{array}$ & 169 \\
\hline Trabajo voluntario & VolunteerActive_1990s2 & $\begin{array}{l}\% \text { de población que participa en trabajo voluntario ac- } \\
\text { tivo }\end{array}$ & 75 \\
\hline Estado de derecho & RuleLaw_2006 & Estado de derecho & 140 \\
\hline Respeto de los derechos civiles & CivilLiberties_2004 & Supresión de libertades civiles (escala invertida) & 133 \\
\hline Corrupción & Corruption3_2006 & Control de la corrupción (escala invertida) & 140 \\
\hline
\end{tabular}

Fuente: Conjunto de datos States Of Nations_2009 (Veenhoven 2009e) 